\title{
Molecular and morphological phylogeny of the parasitic wasp genus Yelicones (Hymenoptera: Braconidae: Rogadinae)
}

\author{
Buntika AREEKUL ${ }^{1,3}$, Miharu MORI ${ }^{1,2}$, Alejandro ZALDIVAR-RIVERÓN ${ }^{1,2}$ and Donald L.J. QUICKE*1,2 \\ ${ }^{1}$ Division of Biology, Imperial College London, Silwood Park Campus, Ascot, Berkshire SL5 7PY, UK; \\ e-mail: d.quicke@imperial.ac.uk \\ ${ }^{2}$ Department of Entomology, The Natural History Museum, Cromwell Road, London SW7 5BD, UK \\ ${ }^{3}$ Department of Biology, Faculty of Science, Chulalongkorn University, Phayathai Road, Bangkok 10330, Thailand
}

Key words. Molecular phylogeny, Braconidae, Rogadinae, Yelicones, 28S rRNA, combined analysis, biogeography

\begin{abstract}
Phylogenetic relationships of the braconid wasp genus Yelicones Cameron are studied using the D2-D3 region of the nuclear 28S rRNA gene, both alone and simultaneously with morphology. The results support a morphology-based phylogeny, presented elsewhere, with Yelicones being divided into two major groups corresponding to the New and Old World faunas. The African and Asian species largely form separate clades except for Yelicones wui Chen \& He from China which is associated with the Afrotropical species. Potential molecular synapomorphies are illustrated.
\end{abstract}

\section{INTRODUCTION}

Yelicones Cameron is a cosmopolitan and highly distinctive genus of parasitic rogadine braconid wasps. The genus is recognised by its robust legs, highly modified and distinctive tarsi with the telotarsus extremely enlarged and the other tarsal segments greatly reduced (Roman, 1910) and by its tridentate mandibles although these are often difficult to observe when they are closed (Quicke \& Kruft, 1995; Areekul \& Quicke, in press a). As in all other Rogadinae sensu stricto, Yelicones sp. are koinobiont endoparasitoids of Lepidoptera larvae, specifically Pyralidae and Crambidae (Shenefelt, 1975; Areekul \& Quicke, in press a). Yelicones mummify the host before pupating within the host (Quicke \& Chishti, 1997; Quicke \& Shaw, in press).

The genus was known for many years after its original description (Cameron, 1887) from only a few specimens collected in the Neotropics (Shenefelt, 1975). However, over the last 40 or so years, many more species have been described, extending the known range to the IndoAustralian (including Oceania), Afrotropical, East Palaearctic and Oriental regions [Fischer, 1961, 1962 (as Pectenopius Fischer, a junior synonym of Yelicones); Togashi, 1980; Papp, 1985, 1989, 1991, 1992; Belokobylskij, 1993a,b; Quicke \& Kruft, 1995; Chen \& He 1997; Quicke et al., 1996, 1997, 1998; Quicke \& Chishti, 1997; Areekul \& Quicke, 2002; Areekul \& Quicke, $2004 a$,b, in press a]. Thus the genus is now known to be widely distributed throughout the Old and New Worlds and has recently been recorded from the West Palaearctic (Spain: Shaw, 1998).

Recently, Areekul \& Quicke (in press a) revised Yelicones species from North, Central and South America. Sixty-three species were described as new and a species level morphological phylogeny based on 116 characters was presented for the world fauna. The results showed a nearly perfect division into two large groups comprising the Old World (OW) and the New World (NW) species, respectively. In the preferred tree in which colour characters were excluded, nearly all the OW species formed a monophyletic group nested within a basal grade of NW taxa, though within the OW clade species from the Australian, African and Oriental regions were largely intermixed, probably due to a lack of phylogenetic signal. However, inclusion of colour characters had a major impact on tree topology in terms of whether the OW or NW species were derived groups: when colour characters were included in the analysis, the NW species appeared to be derived from within a paraphyletic OW grade.

The above conflict in topologies between analyses including or excluding colour characters could be the result of the latter being more homoplastic at higher taxonomic levels, particularly as none of the outgroup taxa are very close to Yelicones. However, the fit of the colour characters on the trees from the simultaneous analysis of colour and morphological characters was higher than the fit of the morphological characters. This suggested that colour character data should not be discounted immediately, though it is also possible that colour characters might be evolving differently from morphological ones, especially when they are involved in aposematic patterns (Areekul \& Quicke, in press b). Here we attempt to resolve the conflict by using molecular data in addition to morphological data. Due to the rarity of this taxon, very few fresh specimens were available for sequencing. A total of 11 species, 3 from the NW and 4 each from Africa and Asia were sequenced. We were not able to obtain fresh material from Australia.

\footnotetext{
* Corresponding author.
} 
TABLE 1. Species included in this study, collection localities and EMBL/GenBank accession numbers.

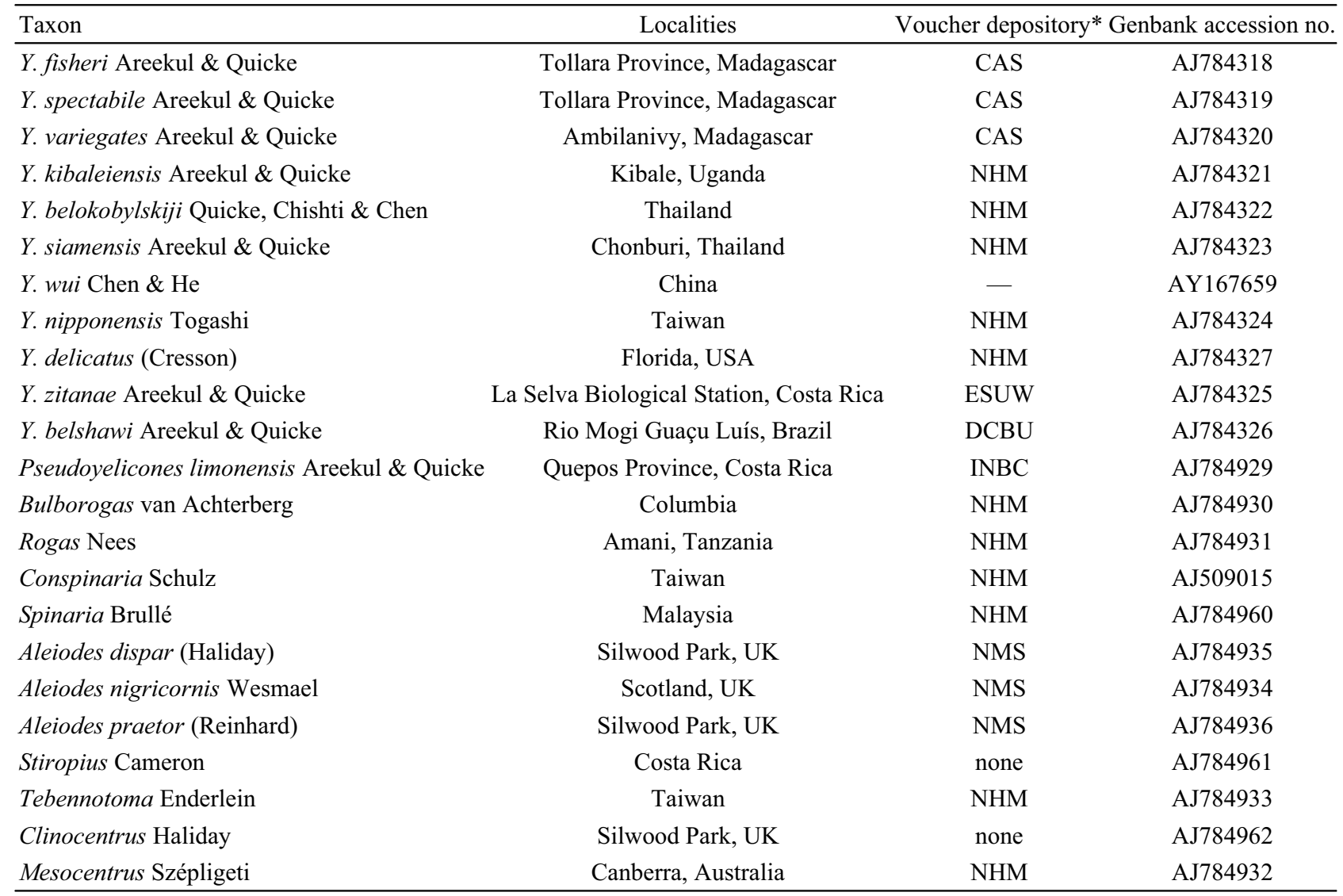

* Abbreviations: CAS - California Academy of Sciences, San Francisco; DCBU - Universidade Federal de São Carlos, São Carlos, São Paulo, Brazil; ESUW - University of Wyoming, Laramie, Wyoming; INBC - Instituto Nacional de Bioversidad (INBio), Santo Domingo de Heredia, Costa Rica; NHM - Natural History Museum, London; NMS - National Museums of Scotland, Edinburgh.

\section{MATERIAL AND METHODS}

\section{Laboratory protocols}

A middle leg was removed from each individual (7 preserved in ethanol and 3 from recently collected dry pinned specimens). Sequence data for $Y$. wui Chen \& He came from Chen et al. (2003). After drying, the tissue was ground in $50 \mu 1$ of $5 \%(\mathrm{w} / \mathrm{v})$ Chelex (Bio-Rad, Hercules, CA, USA)/TE containing $12 \mu \mathrm{g} / \mathrm{ml}$ proteinase $\mathrm{K}$, and digested for $100 \mathrm{~min}$ at $56^{\circ} \mathrm{C}$. Proteinase $\mathrm{K}$ was then heat-inactivated by incubation at $96^{\circ} \mathrm{C}$ for $15 \mathrm{~min}$, and the samples stored at $-20^{\circ} \mathrm{C}$ without separating the supernatant prior to PCR amplification.

Samples were thawed on ice, briefly vortexed and the Chelex pelleted by centrifugation at $16,300 \mathrm{~g}$ for five min prior to removal of $2 \mathrm{ml}$ of supernatant as template for each PCR reaction. PCR reactions were carried out in a $25 \mu \mathrm{l}$ final volume using pureTaq ready-to-go PCR beads (Amersham Biosciences, Buckinghamshire, UK) with $400 \mathrm{nM}$ of each of $28 \mathrm{~S}$ forward (GCG AAC AAG TAC CGT GAG GG; Hancock et al., 1988) and 28S reverse (TAG TTC ACC ATC TTT CGG GTC; Campbell et al., 1993) primers. The PCR program for all the amplifications had an initial $3 \mathrm{~min}$ denaturation at $80^{\circ} \mathrm{C}$, followed by 40 cycles at $94^{\circ} \mathrm{C}$ for $1 \mathrm{~min}, 55^{\circ} \mathrm{C}$ for $1 \mathrm{~min}$, and $72^{\circ} \mathrm{C}$ for 1 min. A 10 min extension followed the final cycle. The PCR products were cleaned with the wizard SV gel (Promega, Madison, WI, USA) and PCR clean up system and then sequenced using the dideoxy terminator cycle sequencing (Applied Biosystems, Inc., Foster City, CA, USA) with an ABI 3700 automated DNA sequencer according to manufacturers instructions.
All species were sequenced in both directions and all pherogram interpretations checked manually.

\section{Taxa investigated}

The species included in this study are listed in Table 1, together with their provenances, depositories and EMBL/GenBank sequence accession numbers. The twelve outgroup taxa chosen for this study were as follows: Aleiodes nigricornis Wesmael, 1838, Aleiodes praetor (Reinhard, 1863), Aleiodes dispar (Haliday, 1833), Pseudoyelicones limonensis Areekul \& Quicke, Rogas Nees, 1818, Spinaria Brullé, 1846, Conspinaria Schulz, 1906, Bulborogas van Achterberg, 1995, Stiropius Cameron, 1911, Clinocentrus Haliday, 1833, Tebennotoma Enderlein, 1912, Mesocentrus Szépligeti, 1900, and of which Tebennotoma was scored from the literature (van Achterberg, 1995). The use of multiple outgroups reflects the general lack of understanding of rogadine relationships (see Zaldivar-Riverón et al., 2004), and in particular the lack of an obvious sister taxon to Yelicones, though Bulborogas and Pseudoyelicones van Achterberg, Panteado-Dias \& Quicke species are similar, perhaps convergently, in body form, being robust with swollen femora and shortened tarsi (see Areekul et al., 2004). Three species of Aleiodes have been included because this is the largest and morphologically most diverse genus of the Rogadinae sensu stricto (Chen \& He, 1997). Zaldivar-Riverón et al. (2004) studied the venom apparatus of 46 species of Aleiodes, six different types of venom apparatus are recognised which partially corresponded with the different subgenera. The three species chosen here represent groups with markedly different types of venom apparatus: A. nigricornis belongs to the subgenus Aleiodes (sensu van 

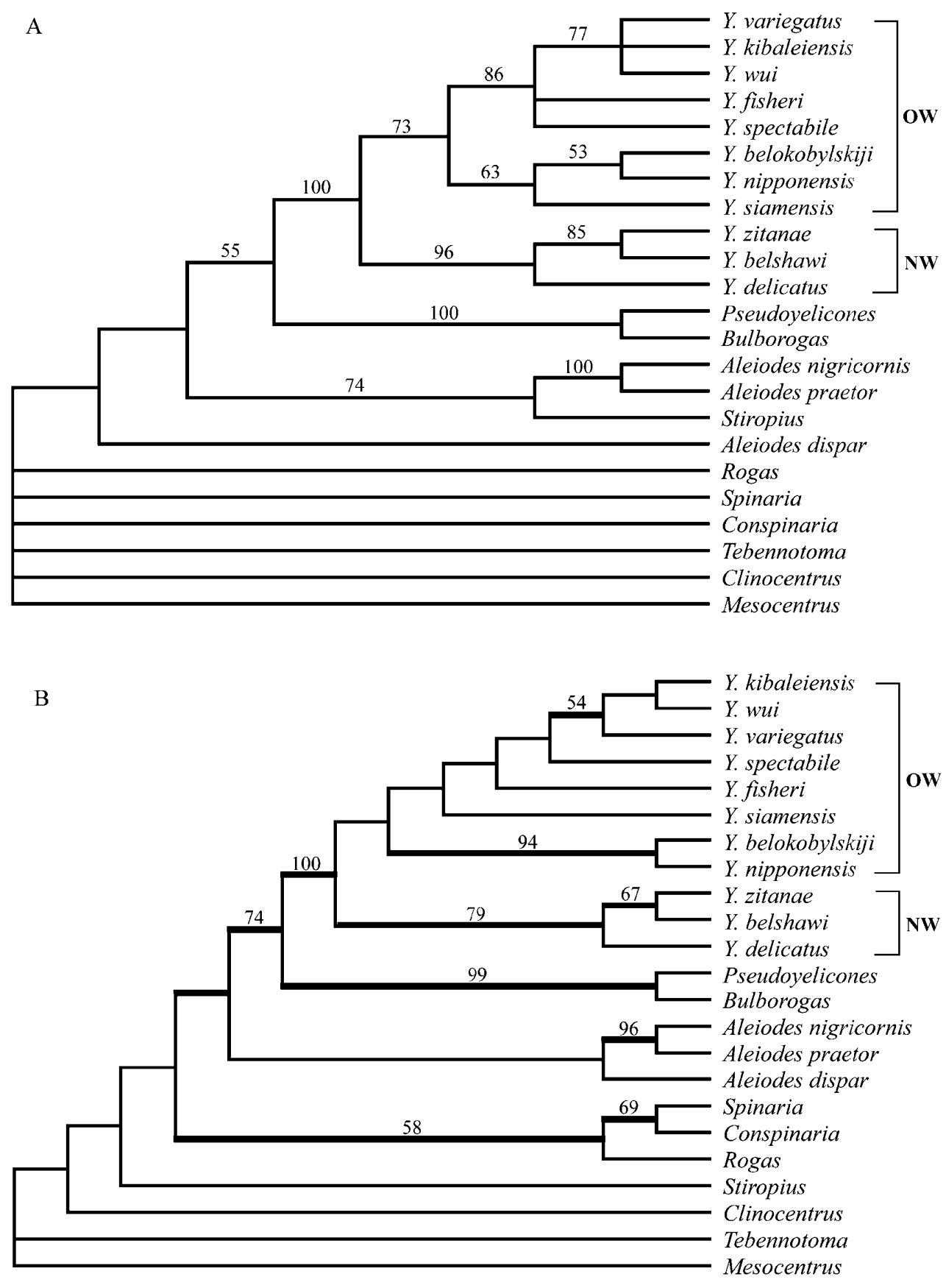

Fig. 1. A - strict consensus of 2 MPTS from molecular-based phylogeny of Yelicones; B - successive approximations weighting tree from the combined analysis. Clades congruent with the strict consensus of MPTs from unweighted analysis are shown in bold. Bootstrap values greater than $50 \%$ from unweighted analyses are indicated

Achterberg, 1991), A. praetor belongs to the subgenus Neorhogas Szépligeti and A. dispar belongs to the subgenus Heterogamus Wesmael. Three members of the Rogas group of genera (Rogas, Conspinaria and Spinaria) were included as they appear to form the sister group of the Aleiodes group and were expected to help show whether Yelicones, Bulborhogas and Pseudoyelicones form a natural group. The betylobraconine, Mesocentrus Szepligeti, was included because betylobraconines also have shortened fore tarsi and robust femora (van Achterberg, 1995) and it is not certain that they are not derived rogadines and thus could be related to Yelicones. Finally, Stiropius of the Stiropiini and Clinocentrus and Tebennotoma of the Clinocentrini were included as these tribes are putatively most basal within the Rogadinae, the former because of their parasitization of leaf-mining microlepidoptera larvae (Gracillariidae and Lyonetiidae), and the latter because of their more exserted ovipositors. Trees were rooted with Tebennotoma.

\section{Phylogenetic analysis}

Sequences were aligned by eye and analyses performed with several ambiguous regions excluded and with remaining gaps treated as uninformative (see Fig. 2). The alignment used with excluded regions indicated is available from http://www.treebase.org/treebase/ (study accession number S1356; matrix accession number M2396). Maximum parsimony analyses were implemented in PAUP* version $4.0 \mathrm{~b} 10$ (Swof- 
ford, 1998) using 10,000 random additions with tree bisection reconnection (TBR) branch swapping holding a maximum of one tree. Relative branch support was assessed by bootstrapping (Felsenstein, 1985) using 500 replicates, each based on 100 random additions.

Eighty morphological characters were used in a combined analysis of molecular and morphological data. The morphological characters used are a subset of those used by Areekul \& Quicke (in press a) that are informative for the Yelicones species investigated here. See appendix 1 for character definitions and appendix 2 for the data matrix.

Successive approximations weighting (SAW: Farris, 1969) using the maximum value of the retention index as the reweighting function (see Quicke et al., 1999; Gauthier et al., 2000) was applied to the combined molecular plus morphological data set to obtain a more resolved tree.

\section{RESULTS}

\section{Molecular results}

Parsimony analysis of 28s rRNA sequence data based on 564 alignable base pairs resulted in 2 most parsimonious trees (MPTs), the strict consensus of which is shown in Fig. 1A (tree length $=386, \mathrm{CI}=0.642, \mathrm{RI}=$ 0.681). The analysis supports the morphological-based phylogeny of Areekul \& Quicke (in press a) in that Yelicones species are divided into 2 large clades, corresponding to OW and NW species, with high bootstrap support (100) (Fig. 1A). Many clear sequence features separate the OW and NW species including several insertions/deletions (indels) that were excluded from or were uninformative in our analyses (Fig. 2, fragments 1, $2,4,6)$. Additionally, a clear resolution of the OW group was obtained, separating Yelicones into largely African and Asian clades (see Fig. 2, fragments 1, 2, 4, 5). The problematic taxon, $Y$. wui from China, being consistantly recovered with the African clade. Yelicones delicatus from North America has a distinctive sequence relative to other Yelicones, with many unique features such as a two base insertion in fragment 6 , a deletion in fragment 1 and a 1 base substitution in fragment 3 (Fig. 2). The outgroup taxa are not well resolved.

\section{Combined analysis}

The combined analysis of morphological and molecular data sets resulted in 6 MPTs (tree length $=787, \mathrm{CI}=$ $0.478, \mathrm{RI}=0.544)$. The strict consensus of these was less resolved than that from the molecular analysis of Yelicones relationships (see thickened branches in Fig. 1B). The NW species were recovered as monophyletic but the OW species were hardly resolved. However, there is more resolution among the basal taxa, with the Rogadini + Yeliconini recovered as monophyletic in addition to the Rogas genus group (Spinaria, Conspinaria and Rogas) being recovered as monophyletic. A more resolved tree was found following successive approximations weighting (SAW): congruence between the SAW tree and the strict consensus tree of 6 MPTs is indicated in bold (Fig. 1B). The OW and the NW species again form two separate clades. However, the Asian species are not recovered as monophyletic except for a clade comprising $Y$. nipponensis $+Y$. belokobylskiji. Y. wui was recovered with the otherwise monophyletic African taxa. The SAW tree shows additional resolution among the outgroup taxa compared with the strict consensus tree from molecular data alone including the three Aleiodes species recovered as monophyletic. Pseudoyelicones and Bulborogas formed a clade with $100 \%$ bootstrap support as found with the molecular data, and again they formed a sister group to Yelicones with slightly decreased bootstrap support (99\%) (Fig. 1).

\section{DISCUSSION}

Our molecular-based phylogeny supports the phylogeny based on morphological characters and indicated that Yelicones species are divided into 2 large clades, the OW and NW species groups. DNA sequences show strong signals separating the $\mathrm{OW}$ and $\mathrm{NW}$, and also differentiate African from Asian species [except for the problematic Y. wui (Fig. 1A)]. In morphology-based analysis including colour characters (Areekul \& Quicke, in press a), $Y$. wui was recovered as sister group to $Y$. variegatus from Madagascar, and within the NW clade in analysis excluding coloration. Y. wui has more or less the same colour pattern as many species found in Africa (e.g. $Y$. variegatus and $Y$. kibaleiensis), their ground-plan body colour being yellow with brown to dark brown distributed throughout the body. This might lead to the recovery of $Y$. wui closely related to $Y$. variegatus and Y. kibaleiensis in morphology-based phylogeny with colour characters included. There are a few species from Asia that have more or less the same colour pattern as Y. wui (e.g. Y. elegans and $Y$. koreanus) but the lack of specimens of these taxa for DNA sequencing prevented us from telling whether these also belong to the same group.

In the morphology-based phylogeny (Areekul \& Quicke, in press a), Y. delicatus was often recovered between the OW and NW groups, especially in analysis including coloration. Its morphology is rather intermediate between that of OW and NW species, (e.g., it has an almost complete occipital carinae and the maximum length of eye is more than 1.8 times the width of eye, both of which are characteristic of most OW species). However, the $28 \mathrm{~S}$ rDNA data clearly show that it belongs to the same monophyletic group as the other two NW species examined (note the apparent synapomorphic substitutions in fragments 3 and 6 and the possibly synapomorphic "AAA" insertion in fragment 6 (Fig. 2).

The molecular and combined analyses presented here do not resolve the initial question (based on morphological analyses including and excluding colour characters) as to whether NW or OW Yelicones species are basal (forming a paraphyletic grade) (Areekul \& Quicke, in press a). Instead they both point to a reasonably wellsupported scenario with both NW and OW groups being monophyletic. However, our taxon sampling was poor especially for the NW clade, and additional taxon sampling will be required fully to resolve this matter.

The molecular phylogeny also confirms a close relationship between Pseudoyelicones and Bulborogas as was suggested by Areekul et al. (2004) based on venom appa- 


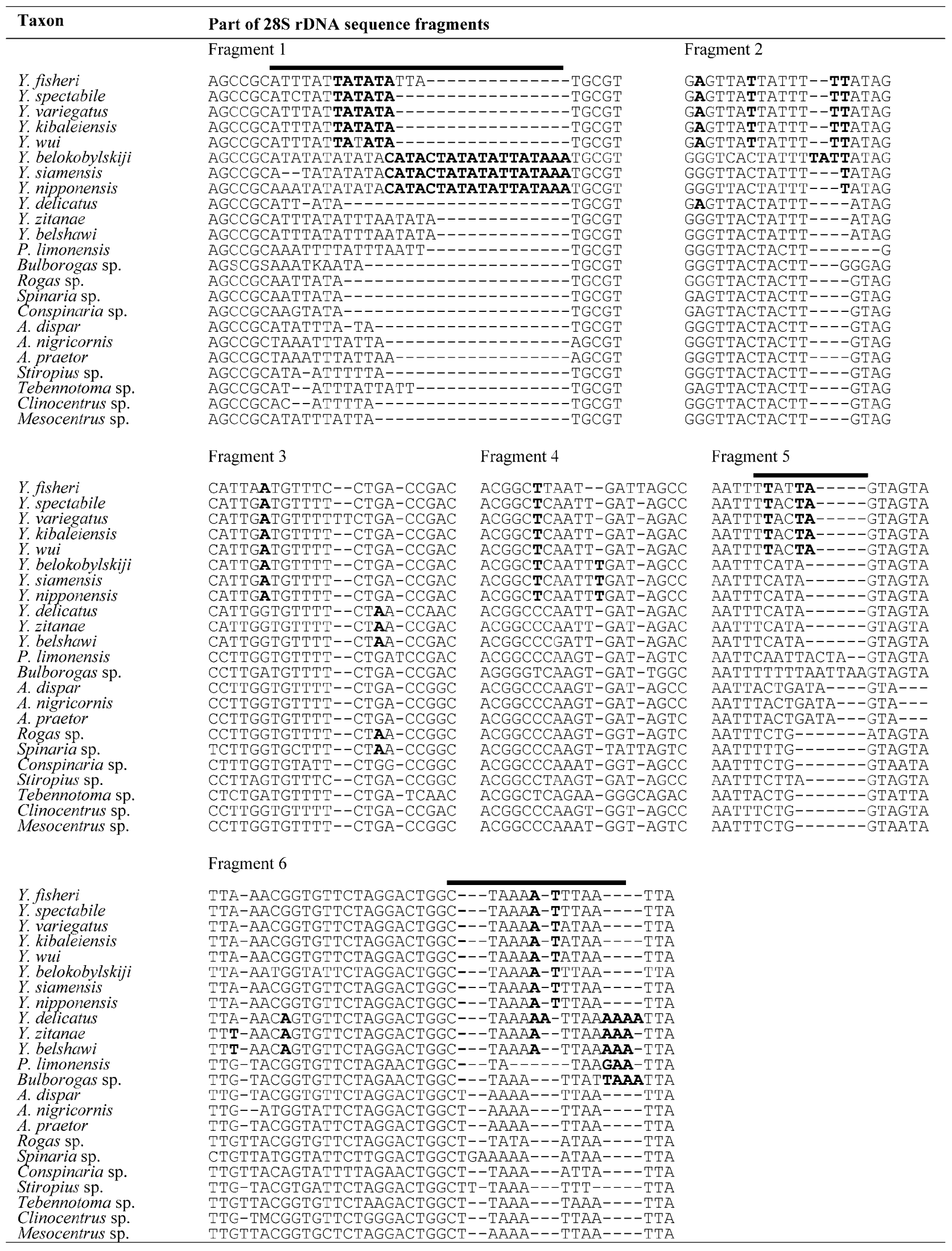

Fig. 2. Six fragments of the D2-D3 region, 28S rRNA arranged by eye showing marked differences between the Old and New World species and between two OW groups (indicated in bold). The dark bars indicate ambiguously alignable sequence blocks excluded from phylogenetic analysis. The fragments correspond to positions in the alignment depicted in Belshaw et al. (1998) as follows; fragment 1 = bases 284-318; fragment 2 = bases 71-87; fragment 3 = bases 252-268; fragment $4=$ bases $177-200$; fragment 5 = bases $330-349$; fragment $6=$ bases $390-416$. 
ratus morphology. Although Pseudoyelicones and Bulborogas appear as a sister group to Yelicones in both analyses (Fig. 1A, B), the bootstrap support for this in the purely molecular tree (Fig. 1A) is only marginal. The secondary venom duct insertion in Pseudoyelicones and Bulborogas is modified (hard) and thus resembles that of members of the Rogas groups of genera (ZaldivarRiverón et al., 2004) whereas secondary venom duct of Yelicones is unmodified, suggesting a more basal position, (unless this modification has been secondarily lost). Unfortunately, the hosts and mummification biology of Pseudoyelicones and Bulborogas are unknown, though features of Yelicones mummies (Quicke \& Shaw, in press) suggest that Yelicones is probably less derived than the Rogas group.

ACKNOWLEDGEMENTS. We thank C. Godoy (INBio, Costa Rica), S.-H. Yen (National Sun Yat-Sen University, Taiwan), B. Fisher (California Academy of Science, USA), M. Sharkey (University of Kentucky, USA) and M. Shaw (National Museums of Scotland, UK) for providing material or permission to sequence material in their care.

\section{REFERENCES}

Achterberg C. van 1995: Generic revision of the subfamily Betylobraconinae (Hymenoptera: Braconidae) and other groups with modified fore tarsus. Zool. Verh. Leiden 298: $1-242$.

Achterberg C. van, Penteado-Dias A.M. \& Quicke D.L.J. 1997: Pseudoyelicones (Hymenoptera: Braconidae: Rogadinae), a new genus from Brazil and Costa Rica. Zool. Meded. Leiden 71: 1-8.

Areekul B. \& Quicke D.L.J. 2002: A new species of Yelicones Cameron (Hymenoptera: Braconidae) from Thailand. PanPac. Entomol. 78: 17-22.

Areekul B. \& Quicke D.L.J. 2004a: A new species of Yelicones Cameron (Hym., Braconidae, Rogadinae) from Afromontane forest in Western Uganda. Entomol. Mon. Mag. 140: 285-290.

Areekul B. \& Quicke D.L.J. 2004b: Three new species of Yelicones Cameron (Hymenoptera: Braconidae: Rogadinae) from Madagascar, with a revised key to Afrotropical species. Afr. Entomol. 12: 243-252.

Areekul B. \& Quicke D.L.J. (in press) a: Systematics of the parasitic wasp genus Yelicones Cameron (Hymenoptera: Braconidae: Rogadinae) and revision of the genus from North, Central and South America. System. Biodivers.

Areekul B. \& Quicke D.L.J. (in press) b: The use of colour characters in phylogenetic reconstruction. Biol. J. Linn. Soc.

Areekul B., Zaldivar-Riverón A. \& Quicke D.L.J. 2004: Venom gland and reservoir morphology of the genus Pseudoyelicones van Achterberg, Penteado-Dias and Quicke (Hymenoptera: Braconidae: Rogadinae) and implications for relationships. Zool. Meded. Leiden 78: 119-122.

Belshaw R., Fitton M., Herniou E., Gimeno C. \& Quicke D.L.J. 1998: A phylogenetic reconstruction of the Ichneumonidea (Hymenotpera) based on the D2 variable region of 28S ribosomal RNA. System. Entomol. 23: 109-123.

CAmeron P. 1887: Family Braconidae, Hymenoptera 1. In F.D. Godman \& O. Salvin (eds): Biologia Centrali-Americana. Taylor \& Francis, London, pp. 312-419.

Campbell B.C., Steffen-Campbell J.D. \& Werren J.H. 1993: Phylogeny of the Nasonia species complex (Hymenoptera: Pteromalidae) inferred from an internal transcribed spacer
(ITS2) and 28S rDNA sequences. Insect Mol. Biol. 2: 225-237.

Chen X.X. \& He J. 1997: Revision of the subfamily Rogadinae (Hymenoptera: Braconidae) from China. Zool. Verh. Leiden 308: $1-187$.

Chen X.X., Piao M.H., Whitefield J.B. \& He J.H. 2003: Phylogenetic relationships within the Rogadinae (Hymenoptera: Braconidae) based on the D2 variable region of $28 \mathrm{~S}$ ribosomal RNA. Acta Entomol. Sin. 46: 209-217.

FARRIS J.S. 1969: A successive approximations approach to character weighting. System. Zool. 18: 374-385.

Felsenstein J. 1985: Confidence limits on phylogenies: An approach using the bootstrap. Evolution 39: 783-791.

FISCHER M. 1961: Zwei neue Opiinen Gattungen (Hym., Braconidae). Ann. Naturh. Mus. Wien 64: 154-158.

Fischer M. 1962: Die Opiinae des Museo Civico di Storia Naturale in Genua (Hymenoptera, Braconidae). Ann. Mus. Civ. Stor. Nat. Giacomo Doria 73: 71-97.

Gauthier N., Lasalle J., Quicke D.L.J. \& Godfray H.C.J. 2000: Phylogeny of Eulophidae (Hymenoptera: Chalcidoidea), with a reclassification of Eulophinae and the recognition that Elasmidae are derived eulophids. System. Entomol. 25: 521-539.

Hancock J.M., Tautz D. \& Dover G.A. 1988: Evolution of the secondary structure and compensatory mutations of the ribosomal RNAs of Drosophila melanogaster. Mol. Biol. Evol. 5: 393-414.

PAPP J. 1985: Braconidae (Hymenoptera) from Korea, 7. Acta Zool. Hung. 31: 341-365.

PAPP J. 1989: A contribution to the braconid fauna of Israel. Israel J. Entomol. 22: 45-59.

PAPp J. 1991: New braconid wasps (Hymenoptera: Braconidae) in the Hungarian Natural History Museum, 2. Ann. Hist. Nat. Mus. Nat. Hung. 83: 145-167.

PApP J. 1992: New braconid wasps (Hymenoptera: Braconidae) in the Hungarian Natural History Museum, 3. Ann. Hist. Nat. Mus. Nat. Hung. 84: 129-160.

Quicke D.L.J. \& Chishti M.J.K. 1997: A revision of the Yelicones species (Hymenoptera: Braconidae: Rogadinae) from Africa and the Arabian Peninsula, with descriptions of four new species. Afr. Entomol. 5: 77-91.

Quicke D.L.J. \& KRUfT R.A. 1995: Species of Yelicones (Hymenoptera: Braconidae: Rogadinae) in North America with descriptions of two new species. Ann. Entomol. Soc. Am. 88: $129-138$

Quicke D.L.J. \& SHAw M.R. (in press): First host records for the rogadine genera Rogasodes Chen and $\mathrm{He}$ and Canalirogas van Achterberg \& Chen (Hymenoptera: Braconidae) with description of a new species and survey of mummy types within Rogadinae s. str. J. Nat. Hist.

Quicke D.L.J., Austin A.D. \& Chishti M.J.K. 1998: Revision of Yelicones (Hymenoptera: Braconidae: Rogadinae) from the Australasian region. Invert. Taxon. 12: 897-928.

Quicke D.L.J., Basibuyuk H.H., FitTon M.G. \& Rasnitsyn A.P. 1999: Morphological, palaeontological and molecular aspects of ichneumonoid phylogeny (Hymenoptera, Insecta). Zool. Scr. 28: 175-202.

Quicke D.L.J., Chishti M.J.K. \& Basibuyuk H.H. 1996: A revision of the Yelicones species (Hymenoptera: Braconidae: Rogadinae) from Central America, with descriptions of sixteen new species. Zool. Meded. 70: 17-61.

Quicke D.L.J., Chishti M.J.K., Chen X. \& Kruft R.A. 1997: Revision of Yelicones (Hymenoptera: Braconidae: Rogadinae) from the East Palaearctic and Oriental regions 
with description of four new species. J. Nat. Hist. 31: 779-797.

Roman A. 1910: Notizen zur Schlupwespensammlunges Schwedischen Reichsmuseums. Entomol. Tidskr. (Stockholm) 31: 109-196.

SHaw M.R. 1998: The surprising discovery of the genus Yelicones Cameron (Hymenoptera: Braconidae) in Western Europe. Br. J. Entomol. Nat. Hist. 11: 15-16.

Shenefelt R.D. 1975: Braconidae 8, Exothecinae and Rogadinae. Part 12. In Van Der Vecht J. \& Shenefelt R.D. (eds): Hymenoptera Catalogus. Junk, The Hague, pp. 1115-1262.

SwOFFord D.L. 1998: PAUP*. Phylogenetic Analysis Using Parsimony (* and other methods) version 4. Sinaeuer, Sunderland, MA, USA.

Togashi I. 1980: Discovery of the genus Yelicones Cameron (Hymenoptera, Braconidae) from Japan. Kontŷu 48: 571-520. Zaldivar-Riverón A., Areekul B., Shaw M.R. \& Quicke D.L.J. 2004: Comparative morphology of the venom apparatus in the braconid wasp subfamily Rogadinae (Insecta, Hemenoptera, Braconidae) and related taxa. Zool. Scr. 33: 223-238.

Appendix 1. Morphological characters used in cladistic analysis, subset from Areekul \& Quicke (in press) that are informative for this study.

\section{Head}

1. Antennae: $0=$ with more than 36 flagellomeres; $1=$ with 30-36 flagellomeres; $2=$ with 29 or fewer flagellomere (ordered)

2. Third flagellomere: $0=$ less than $1.5^{\prime}$ longer than wide; $1=$ more than $1.5^{\prime}$ longer than wide.

3. First flagellomere: $0=$ more than $1.3^{\prime}$ longer than the second; $1=$ less than $1.3^{\prime}$ longer than the second.

4. Maximum length of eye: $0=$ more than $1.8^{\prime}$ maximum width of eye (in lateral view); $1=$ less than $1.8^{\prime}$ maximum width of eye.

5. Eyes: $0=$ glabrous; $1=$ distinctly but weakly setose; $2=$ strongly setose (Fig. 481) (ordered).

6. Eyes: $0=$ emarginate; $1=$ not emarginate.

7. Shortest distance between posterior ocellus and eye/maximum distance across posterior ocelli: $0=$ more than $0.7 ; 1=$ less than 0.7 .

8 . Face: $0=$ densely punctured but without marked transverse striation (Figs 26, 30, 36, 90, 260); $1=$ transversely striate, at least between antennal sockets (Figs 116, 170, 290); 2 = entirely smooth with only sparse small punctures at the bases of setae (Figs 66, 108, 128, 146, 194, 320); 3 = granulate.

9. Face, median carina: $0=$ absent; $1=$ present but incomplete (Figs 170, 188, 493); 2 = present and complete.

10 . Width of face: $0=$ less than $1.35 \times$ height of eye; $1=$ more than $1.35 \times$ height of eye.

11. Occipital carina: $0=$ complete medio-dorsally (Figs 38 , $123,448) ; 1=$ medially narrowly absent (Fig. 285); 2 = medially widely absent (Figs 233, 380, 442, 461); $3=$ completely absent (ordered)

12. Gena: $0=$ less than $0.2^{\prime}$ height of eye; $1=0.2-0.4^{\prime}$ height of eye; $2=$ more than $0.4^{\prime}$ height of eye (ordered)

13. Mandibles: $0=$ bidentate; $1=$ tridentate (Figs 54, 76, 146, 220, 254)

\section{Mesosoma}

14. Mesoscutum: $0=$ coarsely rugulose; $1=$ shiny with more or less dense, deep punctured; $2=$ almost entirely smooth; $3=$ punctate-rugulose.

15. Notauli: $0=$ present and complete (Figs 39, 46, 148, 386, 394,405 ); 1 = absent on posterior half of mesoscutum (Figs 462, 495); 2 = almost completely absent (ordered).
16. Notauli: $0=$ smooth (Fig. 155); 1 = finely punctate (Fig. 1489); 2 = crenulated (Figs 39, 148)

17. Mesoscutum: $0=$ without a mid-longitudinal carina; $1=$ with a mid-longitudinal carina.

18. Precoxa suture: $0=$ present; $1=$ absent.

19. Precoxal suture (if present): $0=$ well developed, wide, extending most of length mesopleuron (Figs 125, 223); 1 = narrow, occupying most of length of mesopleuron (Figs 53, 112, $434) ; 2$ narrow and restricted to antero-medial part of mesopleuron (Figs 63, 119).

20. Scutellum: $0=$ with fewer than 50 setae; $1=$ with $50-100$ setae; 2 = with more than 100 setae (ordered).

21. Scutellum medio-posteriorly: $0=$ smooth; $1=$ punctured; $2=$ rugulose $; 3=$ formed into a strong keel.

22. Metanotum: $0=$ simple (Fig. 443 ); $1=$ with mid-posterior pit (Figs 453, 484).

23. Number of carinae in scutellus sulcus between two outer ones: $0=$ more than 5 (Figs 387, 426, 433, 463); $1=4$ or 5 (Fig. 444); $2=3$ (Fig. 196) (ordered).

24. Propodeum: $0=$ simple; $1=$ with inverted " $U$ "-shaped carina antero-medially (Figs 198, 210, 217, 229); 2 = with inverted "V/Y"-shaped carina antero-medially (Figs 362, 491, 457). State 2 appears to arise from state 1 via a narrowing and loss of the gap between the carinae at the anterior end of the propodeum, therefore we have treated it as ordered in relevant analyses (ordered).

25. Propodeum: $0=$ antero-submedially foveate/rugose (Figs 138, 186, 390, 396); 1 = antero-submedially smooth (Figs 48, $57,72,105,210,224)$.

26. Propodeum, sublateral carinae: $0=$ without distinct sublateral carinae (Figs 48, 138); $1=$ distinct on posterior half but not complete (Figs 167, 288, 435); 2 = with well-developed, continuous sublateral carinae (Figs 57, 81, 224, 229) (ordered).

27. Propodeum: $0=$ postero-medially without "A"-shaped arrangement of carinae (Figs 47, 74, 156); 1 = postero-medially with "A"-shaped arrangement of carinae (Figs 113, 288, 426).

28. Propodeum, mid-longitudinal carina: $0=$ absent; $1=$ present.

29. Propodeum: $0=$ without spine; $1=$ with a pair of spines postero-laterally.

30. Mid-ventral suture of mesoscutum: $0=$ smooth; $1=$ crenulated.

\section{Fore wing}

31. Fore wing vein $\mathrm{r}$ arising: $0=$ before middle of pterostigma; 1 = beyond middle of pterostigma.

32 . Fore wing vein $1-\mathrm{SR}+\mathrm{M}: 0=$ sinuous, markedly curving towards wing tip after arising from 1-M (Figs 64, 82); $1=$ straight or with simple curve, not curving anteriorly after arising from 1-M (Figs 24, 35, 88, 114, 133).

33. Fore wing subdiscal cell: $0=$ less than $5.5^{\prime}$ longer than maximally wide; $1=$ more than $5.5^{\prime}$ longer than maximally wide (excluding veins).

34. Fore wing vein $1-\mathrm{CU}: 0=$ more than $0.5^{\prime} 2$-CU1; $1=$ $0.3-0.49^{\prime} 2$-CU1; 2 = less than $0.3^{\prime} 2$-CU1 (ordered).

35 . Fore wing vein $2-\mathrm{CU} 1: 0=$ more than $2.3^{\prime} 3-\mathrm{CU} 1 ; 1=$ 2.0-2.3' 3-CU1: 2 = less than 2.0'3-CU1 (ordered).

36. Fore wing vein $3-\mathrm{SR}$ : $0=$ longer than $\mathrm{r}-\mathrm{m}$ (Figs 88, 126): $1=$ shorter than $\mathrm{r}-\mathrm{m}$ (Figs 98, 106).

37. Fore wing vein $\mathrm{r}: 0=$ longer than $3-\mathrm{SR}$ (Figs 35, 106, 114, 133); 1 = shorter than 3-SR (Fig. 64).

38. Pterostigma: $0=$ length less than or 3 ' width; $1=$ length more than $3^{\prime}$ width

39. Fore wing $\mathrm{m}+\mathrm{cul}$ : $0=$ straight apically; $1=$ curved apically (Fig. 82). 
40. Fore wing length: $0=$ less than $4.0 \mathrm{~mm} ; 1=4.0-6.0 \mathrm{~mm}$; $2=$ more than $6.0 \mathrm{~mm}$ (ordered).

41. Fore wing CU1a: $0=$ not weak; $1=$ weakened.

42. Fore wing CU1b: $0=$ present; $1=$ absent.

\section{Hind wing}

43. Hind wing marginal cell: $0=$ evenly setose; $1=$ with glabrous patch.

44. Hind wing vein SR: $0=$ more or less straight; $1=$ weakly sinuous; 2 = strongly sinuous.

45. Hind wing vein SR: $0=$ straight or curving anteriorly at apex; $1=$ curving posteriorly at apex.

46. Hind wing vein $2-\mathrm{SC}+\mathrm{R}: 0=$ strongly longitudinal (Figs $5,6,7) ; 1=$ weakly longitudinal (Fig. 430); $2=$ interstitial; $3=$ short transverse (Fig. 5); $4=$ long transverse (Fig. 6) (ordered).

47. Hind wing $\mathrm{m}+\mathrm{cu}: 0=$ absent; $1=$ present.

48. Hind wing vein $\mathrm{m}+\mathrm{cu}$ (when present): $0=$ curving strongly towards base of wing (Fig. 364): 1 = curving distinctly but weakly towards base of wing; $2=$ more or less straight (Fig. 82); 3 = curving distinctly away from base of wing (Fig. 42).

49. Hind wing vein $\mathrm{m}+\mathrm{cu}$ (when present): $0=$ antefurcal (Figs 4,5); 1 = interstitial (Fig. 6); 2 = weakly but distinctly postfurcal by up to $0.1^{\prime}$ length of vein 1r-m (Fig. 230); 3 = strongly postfurcal by approximately $0.2^{\prime} 1 \mathrm{r}-\mathrm{m}$ (Fig. 7) (ordered).

50. Hind wing $\mathrm{M}+\mathrm{CU}$ : $0=$ less than $1.0^{\prime} 1-\mathrm{M} ; 1=1.0-1.5^{\prime}$ $1-\mathrm{M} ; 2$ = more than $1.5^{\prime} 1-\mathrm{M}$ (ordered).

51. Hind wing vein 2-M: $0=$ running straight to wing margin; $1=$ curving parallel to wing margin at apex.

\section{Legs}

52. Fore tibia: $0=$ simple; $1=$ with a mid-longitudinal smooth or longitudinally striate line; 2 = with a well-developed midlongitudinal ridge.

53. Fore tarsus: $0=$ normal; $1=$ fore tarsus shorter than fore tibia; 2 = fore tarsus much shorter than fore tibia (ordered).

54. Hind basitarsus: $0=$ more than $0.4^{\prime}$ longer than tibia; $1=$ less than $0.4^{\prime}$ tibia.

55. Hind basitarsus: $0=$ not flat and not enlarged; $1=$ flat and enlarged.

56. Tarsal claws: $0=$ not pectinate; $1=$ strongly pectinate.

\section{Metasoma}

57. T1 sculpture: $0=$ striate; $1=$ rugose, rugulose; $2=$ punctured to smooth.

58. $\mathrm{T} 1$ spiracle: $0=$ more than 0.75 distance between posterior margin of dorsope and posterior margin; $1=$ less than 0.75 distance.

59. T1 dorsal carinae: $0=$ uniting before the level of spiracles (Figs 13, 29, 65); $1=$ uniting at or behind the level of spiracles (Figs 89, 307, 337, 379).

60. Dorso-lateral carinae of first tergite: $0=$ well-developed; $1=$ half length of $\mathrm{T} 1 ; 2=$ absent (ordered).
61. T2: $0=$ with large, smooth mid-basal area (Figs 13, 59, 163); 1 = without or with only trace of mid-basal area (Fig. 43).

62. T2: $0=$ largely striate (Figs 29, 43, 65); $1=$ at most basal half striate (Figs 13, 49); 2 = completely smooth or at most with a few striae very close to base (Figs 75, 89, 253) (ordered).

63. T2 mid-longitudinal carina: $0=$ present; $1=$ absent.

64. T2 mid-longitudinal carina (if present): $0=$ complete (Figs 29, 43, 65); 1 = nearly complete or just beyond half-length (Figs 181, 193); 2 = present but not extending beyond midlength (Figs 13, 199, 253) (ordered).

65. T2 width/length: $0=$ less than $2.0 ; 1=2.0-2.5 ; 2=$ more than 2.5 (ordered).

66. Second suture: $0=$ deep and crenulated (Figs 29, 43, 65);

$1=$ deep and smooth (Figs 13, 49, 83); 2 = shallow but distinct (Fig. 151); 3 = obsolescent.

67. Second suture: $0=$ straight (Figs 151,175$) ; 1=$ weakly to strongly sinuate (Fig. 83).

68. Length of T2/T3: $0=0.63-1.0 ; 1=$ more than 1.0 .

69. T3: $0=$ largely striate; $1=$ half striate; $2=$ hardly striate (ordered).

70. If $\mathrm{T} 3$ not completely striate then: $0=$ smooth; $1=$ sparsely punctured; $2=$ densely punctured; $3=$ granulate; $4=$ transverse carinae.

71. Ovipositor tip: $0=$ weakly sclerotised; $1=$ strongly sclerotised, dark.

\section{Internal anatomy}

The following characters of the venom apparatus are taken from Zaldivar-Riverón et al., (2004) and Areekul et al. (2004).

72. Insertion of secondary venom duct: $0=$ anterior or medially on reservoir; $1=$ posterior on venom reservoir.

73. Base of secondary venom duct: $0=$ without internal filaments: $1=$ few or numerous internal filaments.

74. Secondary venom duct insertion on to reservoir: $0=$ not recessed; 1 = recessed, with well defined and numerous internal filaments.

75. Secondary venom duct: $0=$ simple or with no evident sculpture; 1 = spiral sculpture; 2 = "hexagonal" type sculpture.

76. Secondary venom duct: $0=$ considerably long, at least $2 \times$ as long as the venom reservoir length; $1=$ distinctively short, not more than $2 \times$ as long as wide.

77. Secondary venom duct: $0=$ branched into tertiary and subsequent gland ducts, without insertion of venom gland; $1=$ not branched, with two venom gland bunches, one at its middle and the other at its end.

78. Secondary venom duct: $0=$ without flange; $1=$ with a distinct flange.

79. Tertiary venom duct: $0=$ parallel-sided; $1=$ medially expanded.

80. Tertiary venom duct: $0=$ symmetric; $1=$ asymmetric.

Received January 7, 2005; revised and accepted July 8, 2005 